\title{
A OFENSIVA POLÍTICA DOS EUA SOBRE A AMÉRICA LATINA NA VISÃO ALEMÃ̃: UMA FACE DO CONFRONTO INTERIMPERIALISTA (1938)
}

\author{
Helder Gordim da Silveira*
}

\section{1 - INTRODUÇÃO}

A situação particular da inserçâo latino-americana no sistema capitalista internacional nos anos 30 - durante a conjuntura de crise generalizada do sistema apresentava um acirrado processo de disputa político-econômica entre os principais centros hegemônicos internacionais, em torno da manutençăo ou ampliação de suas respectivas posiçōes no subcontinente.

Os EUA e a Alemanha, na condição de potências-líderes de dois sistemas imperialistas antagônicos, estabelecem, notadamente a partir da segunda metade da década, estratégias mais ou menos sistemáticas de penetraçăo nos organismos econômicos e políticos latino-ameicanos, com vistas na urgente manutenção (e conquista) de importantes setores de mercado periférico.

Ademais, à medida que o conflito militar se desenhava mais nitidamente no quadro da crise capitalista, o controle político e a preservaçăo de zonas estratégicas - sobretudo por parte dos EUA - intensificam os interesses destes centros de poder internacional na América Latina.

No plano político-ideológico, particularmente, este processo de disputa traduzia-se no confronto entre o discurso pan-americanista, por parte dos EUA, e a propaganda nacional-socialista, desencadeada pela Alemanha no subcontinente, sobretudo nos países do Cone Sul.

Estudos Ibero-Americanos. PUCRS, v. XVIII, n. 1, p. 19-27, julho, 1992 
O Pan-americanismo, negociado diplomaticamente e veiculado por meio da imprensa, do cinema e do intercâmbio cultural — no âmbito da Política da Boa Vizinhança, de pós 1933 - parecia controlar os principais setores de formação da opinião pública latino-americana e possuir trânsito preponderante na maioria dos círculos governamentais, embora com resistências bastante consideráveis em todas essas áreas. ${ }^{1}$

O nacional-socialismo, por seu turno, apresentava-se com grande vitalidade ideológica, sobretudo em virtude da crítica feroz que exibia ao liberalismo político e económico em crise, mas também pela "capacidade mobilizadora das massas, a aparência revolucionária e a promessa de realização de uma nova ordem ${ }^{2}{ }^{2}$ Contudo, o nazismo ressentia-se da fraqueza determinada por sua "dimensão irredutivelmente alemă ${ }^{3}$, o que limitava severamente sua eficácia às populaçōes de imigrantes e seus descendentes. O milagre alemão, entretanto, impressionava vivamente importantes esferas de influência política latino-ameicanas e, sobretudo, era alvo de grande admiraçáo nos setores militares, principalmente no Brasil, na Argentina e no Chile, mas não apenas nesses países. ${ }^{4}$

Considerando de forma particular o ano de 1938 - marcado pelo recrudescimento da crise européia e pela definiçăo mais nítida da proximidade da guerra - este trabalho pretende propor uma análise aproximativa sobre a reaçăo da diplomacia alemă diante da notável ofensiva política dos EUA sobre a América Latina no período, refletida, entre outros pontos, em um programa de propaganda anti-germânica, a partir de entăo bem mais enfático e decidido.

Buscamos verificar como as representaçōes diplomáticas alemãs nos países do subcontinente interpretam e de que forma sugerem a Berlim reorientaçōes de atitudes e modos de reação contra o incremento da política anti-germânica desencadeada por Washington. ${ }^{5}$

Evidenciamos os aspectos da referida reação alemã que parecem fundamentais, a julgar pela visáo de Berlim e dos representantes germânicos na América Latina: a questấo do controle da grande imprensa na regiấo pelas agências de notícias norteamericanas e o problema do germanismo associado à ação do Partido Nazista no subcontinente.

\section{2 - A QUESTÃO DA IMPRENSA}

Um dos temas de maior destaque e de reiterada ênfase na correspondência diplomática alemã das embaixadas latino-americanas diz respeito ao enorme grau de 
influência dos EUA na grande imprensa dos países latinos e, conseqüentemente, a abundante propaganda anti-germânica eiculada por esses órgåos de comunicaçăo de massa.

Von Schoen, embaixador no Chile, em relatório de 8 de março, dá conta de que "uma espécie de psicose de guerra" (p. 19) estava sendo produzida naquele país por meio da imprensa americana, notadamente a agência United Press, que, segundo o diplomata, detinha um "completo monopolio sobre as notícias" (p. 19). É evidente que a expectativa de guerra somada ao pan-americanismo e à boa-vizinhança de Roosevelt criava um ambiente francamente desfavorável à Alemanha, o que parece ser, de fato, a preocupação central de Von Schoen.

Von Rudt, da embaixada no México, em relatório de 8 de abril (p. 31), apesar de nâo dar grande importância à propaganda anti-germânica no país, chegando a considerá-la quase inexistente, năo deixa de reconhecer que a imprensa americana $\mathrm{e}$ os serviços telegráficos influenciavam a opinião pública "muito desfavoravelmente contra nós" (p. 32), nos termos do embaixador.

Bem mais enfático quanto à questăo é o embaixador alemão no Uruguai, em relatório de 21 de abril: "... é de grande importância o resultado indireto da influência dominante da United Press e da Associated Press. Essas duas agências, com seus serviços de notícias, dominam tăo completamente o público que pelo menos os problemas europeus são vistos sobretudo através das lentes norte-americanas". (p. 35)

Ritter, o embaixador no Brasil, parece ser o único a não emprestar relevância à questão da propaganda anti-germânica pela imprensa. Em relatório de 30 de março, atribui a apenas "um setor da imprensa" (p. 27) a veiculaçấo sistemática de artigos anti-germânicos cuja inspiraçấo seria ora, segundo o diplomata, de "judeus, emigrés, padres católicos irados, alemăes descontentes e desafetos" (p. 27) e, em muito pouca medida de "verdadeiros inimigos da Alemanha" (p. 27). Contudo, o próprio Secretário de Estado alemăo, Weizsacker, em telegrama a Ritter, de 14 de maio (p. 53), parece năo compartilhar da opiniáo do embaixador a respeito da questáo imprensa. Informando a Ritter que recebera o embaixador brasileiro na Alemanha para tratar da delicada questão das prisōes de agentes do partido no Brasil por acusaçáo de envolvimento na tentativa de golpe integralista. Durante a entrevista, o que evidencia a importância que dava à questáo, mencionara que "temos observado a violenta propaganda norte-americana contra os alemães no Brasil" (p. 53) e não deixara mesmo de sugerir ao Representante brasileiro em Berlim que este insistisse junto a seu governo no sentido de que fossem "tomadas medidas contra essa atividade inflamatória dos jornalistas norte-americanos" (p. 54). 
Na verdade, a Imprensa assume tal importância no episodio motivador do referido telegrama, que o próprio Ritter sugere que a imprensa alemã passe a tratar o caso brasileiro com maior dureza, no que é atendido pelo Secretário de Estado (p. 54). Quanto à mesma questão, Ritter, de forma um tanto contraditória em relaçáo à opiniăo que anteriormente emitira, dá grande importância, em telegrama de 13 de maio, à propaganda da América do Norte, a qual, segundo o diplomata, "acusa os alemães de se terem organizado na véspera da revolta de ontem" (p. 51). Queixa-se ainda Ritter da condescendência do governo brasileiro para com tal propaganda (p. $51)$.

Em memorando do Secretário de Estado de 18 de maio, o "término da campanha de imprensa" (p. 66) é colocado como condiçáo fundamental para a normalização das relaçōes entre o Brasil e a Alemanha, no que se refere ao problema das prisōes mencionadas.

A ofensiva ideológica dos EUA é igualmente refletida na imprensa argentina, a julgar pelo relatório do Embaixador Termann, de 18 de maio (p. 75). Procurando apontar as principais razões determinantes do sentimento anti-germânico entăo evidenciado em importantes países sul-americanos, o Embaixador enfatiza: "nem é necessário explicar-se que, como no Brasil, são principalmente os grupos norte-americanos que estăo atrás de toda essa propaganda anti-germânica" (p. 75). No mesmo relatório, o Embaixador dá conta de que pela primeira vez os grandes jornais diários, conduzidos por La Prensa - considerado "muito controlado em tais assuntos" (p. 77) - haviam criticado duramente o aparecimento de unidades esportivas em uniformes pardos durante a parada memorial do Langemarck. Os jornais teriam ainda criticado o chamado "concerto das mil crianças alemãs" (p. 77), no qual, queixa-se o diplomata, apenas $25 \%$ das crianças eram efetivamente de nacionalidade alemã, segundo a jurisprudência argentina (p. 77). O embaixador menciona ainda a existência de outros episódios sem maior significância que teriam sido objeto de larga exploraçáo pela imprensa. Cita o caso de uma escola alemă no território de Missiones, que ostentava a denominaçăo Escola Nacional Socialista Alemã, o que teria causado a intervençăo do governador e a prisáo do líder da célula local.

É na América Central, entretanto, que a diplomacia alemã sente de forma mais direta e incisiva o controle da imprensa por parte dos EUA. Não é outro o sentido da declaraçăo do Ministro na América Central e no Panamá, Reinebeck, em relatório de 14 de novembro: "Os resultados da propaganda inescrupulosa da imprensa norte-americana săo evidentes aqui em um grau amedrontador" (p. 14). E, referindo-se à recente crise européia: "poucas vezes todo um povo foi tăo unanimemente orientado contra a Alemanha (...)" (p. 140). Ainda em relação à crise, queixa-se o diplo- 
mata: "a técnica das manchetes excedeu-se em seus esforços para acusar uma Alemanha belicosa de ameaçar a paz mundial. Os raros noticiários que faziam justiça à posiçăo alemă eram sistematicamente colocados em lugar sem destaque, freqüentemente nas últimas páginas ou páginas internas dos jornais" (pp.139-140). Conclui ainda o diplomata: "declarações pró-alemáes năo conseguiam espaço ou público" (p. 140).

Como reação a tal situaçáo, o Ministro chega a sugerir o estabelecimento de uma agência de notícias com sede na Guatemala, a qual já estaria sendo preparada (p. 140).

Durante a reuniáo em Montevidéo dos chefes de Missáo na Argentina, Brasil, Chile e Uruguai, em julho, a questão imprensa é tratada de forma particular e săo sugeridos os termos gerais de uma reaçăo diante do controle norte-americano dos órgăos de divulgaçăo, em vista do recente incremento nestes da propaganda anti-germânica (p. 107). Os embaixadores Ritter, Von Thermann, Von Schoen e o Ministro Lagmann concluem que a propaganda alemă não deveria ser veiculada em órgăos da imprensa local, por motivos 6 bvios. Advertem que "muito mais dinheiro tem que ser gasto" (p. 107) na tentativa de contrabalançar a recente ofensiva norte-americana no setor. Chegam a sugerir em relação ao caso que "a única forma apropriada seria a de obter influência financeira dominante sobre um grande jornal diário" (p. 107). E acrescentam: "a pressão exercida pela colocaçăo e retirada de anúncios năo é suficiente neste caso" (p. 107).

Os diplomatas sugerem ainda, de forma complementar, o envio de jornais alemáes para as Missóes na América do Sul, a suplementação dos serviços da Transocean entre a Alemanha e a América do Sul, bem como a extensáo e o desenvolvimento das atividades do transmissor em ondas curtas (p. 108).

Em suma, comparando-se o peso das queixas com o do possível alcance da reação sugerida, a balança parece pender para o lado dos fatores que motivaram aquelas. A diplomacia alemã, a julgar pelos documentos referidos, mostra-se enormemente assustada e, em larga medida, impotente diante do monopólio de informaçăo que os EUA manipulam, pode-se igualmente inferir, com extrema eficácia e precisão de objetivos.

\section{3 - O GERMANISMO E A AÇĀO DO PARTIDO}

Se a ofensiva norte-americana no setor da grande imprensa determinou, como reação por parte da diplomacia alemă, apenas uma espécie de constataçáo da impos- 
sibilidade de fazer frente, ao menos em pé de igualdade, à situaçăo, o mesmo não se verifica em relaçăo às mudanças de estratégia dos programas culturais e da açăo do partido junto aos grupos de imigrantes, sobretudo no Brasil e na Argentina. Neste caso, a reaçáo contra o antigermanismo parece traduzir-se em um tipo de recuo tático. Uma vez perdida grande parte das possibilidades de atuaçăo junto à opinião pública dos países latinos, a diplomacia alemă năo parece disposta a permitir que isso prejudique a açăo junto aos imigrantes e seus descendentes, o que parece, de fato, ser prioritário. O referido recuo revela-se na sugestão das embaixadas no sentido de que a açăo do partido fosse, na medida do possível, completamente dissociada da açăo dita "cultural" junto aos imigrantes. Tal sugestáo significava o abandono imediato das manifestações mais ostensivas dos rituais nazistas, muito freqüentes até então, notadamente no sul do Brasil e na Argentina, importantes núcleos de colonizaçăo germânica. Parecia vital que a açăo do partido năo se confundisse com a preservaçăo e o exercício das tradiçóes germânicas. Tratava-se, na verdade, de camuflar ao máximo a atuaçăo política com o objetivo de preservá-la para momentos mais favoráveis, talvez então aguardados.

Parece ser essa precisamente a preocupaçăo de Ritter, em relatório de 30 de março (p. 27). O diploma expressa, entāo, grave preocupação com as atitudes do governo Vargas contra organizaçốes e membros do Partido. Segundo Ritter, o governo brasileiro demonstrava fortes temores de que a colônia alemã fosse inevitavelmente alvo da açáo do Partido, o que explicaria, na visão do embaixador, "a supressão ocasional de escolas alemãs e da língua alemã nas Igrejas, assim como a atitude hostil contra toda forma de ação unida e exclusiva dos elementos germânicos (...)" (pp. 28-29). Ritter já expressa, então, a estratégia de desvincular o germanismo da açăo política, afirmando que já fizera esforços no sentido de argumentar junto ao governo de que a ação do Partido era "estritamente limitada aos nacionais alemáes" (p. 28), o que excluiria os Volksdeutsche do sul. No mesmo relatório Ritter parece considerar irreversível a proibição das atividades do partido nos estados daquela regiáo.

Com a tentativa de golpe integralista, Ritter tem de enfrentar sério comprometimento nas relaçōes Brasil-Alemanha, diretamente relacionada à questăo das atividades do partido. Conforme mencionamos, acusava-se a organização nazista de haver participado diretamente no episódio. De boatos pela imprensa, passou-se rapidamente à prisão de elementos do partido de nacionalidade alemá, com base em provas frágeis ou praticamente inexistentes, segundo o julgamento da diplomacia germânica. No episódio, parece novamente ficar evidente a preocupaçáo alemá em proteger a colônica e o germanismo da perseguiçáo ao partido, mesmo sob o preço de um recuo nas atividades deste. De fato, um telegrama de 14 de maio (p. 53), o 
secretário de Estado Weizascker faz ver a Ritter que, apesar da gravidade da prisão de nacionais alemăes ligados ao Partido, o que de fato estava em jogo na questâo era "o prestígio e a preservaçăo da colônia alemă no Brasil" (p. 54). Em memorando de 18 de maio (p. 65), ainda tratando do mesmo problema, Weizascker é bastante claro quanto à questão. Enfatiza na ocasiáo que alertara o embaixador brasileiro em Berlim de que "sobretudo protegemos os interesses dos nacionais alemáes, mas que a opiniăo pública alemã năo pode ficar indiferete se Volksdeutsche foram perseguidos apenas por causa de sua origem, e se náo se puserem freios aos ataques contra a civilizaçăo e a cultura germânica" (p. 66). Parece clara a intençấo de desvincular a atuação dita cultural das atividades mais explicitamente políticas, embora fosse realmente difícil esconder o fato de que aquelas constituiam um meio para o desenvolvimento destas, o que não passava desapercebido aos setores antigermânicos do governo e da opinião pública no Brasil.

A orientação do Secretário de Estado parece ser idêntica em relação aos problemas com as atividades do partido na Argentina. Em memorando de 18 de maio, endereçado a Thermann (p. 71). Weizsacker relata a entrevista que tivera a respeito com o representante argentino na Alemanha. Este, segundo o relato do Secretário, revelara, na oportunidade, a insatisfaçăo com o modo ostensivo pelo qual o Partido atuava em solo argentino. O diplomata referia-se especificamente aos "comícios, tropas uniformizadas, exercícios e fatos semelhantes (...) - coisas que não agradavam ao gosto do povo argentino" (p. 72). Na verdade, a questāo da Dupla Nacionalidade complicava sobremaneira os problemas com a Argentina, o que foi devidamente salientado pelo representante diplomático daquele país junto ao Secretário de Estado Alemâo. Vale dizer, na Argentina tornava-se bem mais difícil para a diplomacia alemá vender a imagem de um partido atuante apenas junto aos nacionais alemães, com exclusão dos Volksdeutsche, pois na verdade, era impossível para Argentina e Alemanha chegarem a um acordo a respeito de quem, juridicamente, era alemão ou argentino de origem alemă. Apesar da gravidade adicional do problema na Argentina, o Secretário de Estado alemăo parece fazer suas as sugestões do representante sulamericano no sentido de, ao menos, amenizar o problema. Sugerira, nesse sentido, o Secretário de Estado alemão que "nós deveríamos reorganizar nossas organizações partidárias na Argentina e substituí-las por outras menos agressivas e de aparência inofensiva" (p. 73). Acresce ainda Weiszacker, certamente como uma sugestāo de conduta, que o representante argentino em Berlim sugerira que o Partido passasse a se conduzir naquele país "de maneira năo política e năo oficial" (p. 73). Em suma, o recuo tático nas açōes políticas alemãs a que vimos fazendo referência, parece também verificar-se no caso argentino. Em relatório, igualmente de 18 de maio (p. 75), 
o embaixador na Argentina revela também a reiterada preocupação alemã em não permitir que a onda antigermânica e de perseguiçáo ao partido na América Latina se estendesse ao elemento Volksdeutsche e à "civilizaçăo germânica". Diz Thermann muito claramente: "se (...) nos perguntarmos como ainda será possível salvar o que possa ser salvo do elemento germânico aqui, o problema de separar nacionais alemães dos Volksdeutsche surge necessariamente" (p. 79). Uma vez realizada tal separaçăo, o Partido poderia atuar junto aos nacionais alemães, sugere o embaixador, sob a forma de "uma associaçâo com objetivos puramente culturais" (p. 79), a qual evidentemente "teria de ser dirigida inteiramente de acordo com as linhas do nosso movimento" (p. 80). Quanto aos Volksdeutsche, teriam a incumbência precípua de "manter as grandes instalaçōes alemãs para futuras geraçóes, tais como o Hospital alemâo, as escolas, os centros médicos, os clubes, as Igrejas etc." (p. 80). Ou seja, trata-se novamente da estratégia de manter o germanismo, tanto quanto possível, dissociado das atividades claramente políticas, sempre como um recuo temporário diante da conjuntura desfavorável, como a expressão "geraçóes futuras", utilizada por Thermann, parece deixar claro. Em novo relatório de 7 de junho (p. 93), Thermann volta a insistir na tese do recuo: "é da maior importância que não lhes forneçamos motivos para provocaçốes de qualquer espécie" (p. 94).

Tal posicionamento de recuo político e preservação cultural (esta obviamente com finalidades políticas, em última análise), parece ser inteiramente ratificado e formalizado por ocasião da reunião em Montevidéo dos chefes de Missáo na Argentina, Brasil, Chile e Uruguai, acima mencionado. $\mathrm{Na}$ análise da posiçáo alemă na conjuntura política latino-americana, os diplomatas consideram absolutamente insispensável que o país repudie, a nível oficial, qualquer acusação de que tenha objetivos ligados a planos de poder na América Latina e que "limite sua ação a objetivos culturais e econômicos" (p. 104). Advertem claramente: "Em Lima, provavelmente será feita uma tentativa para esmagar as organizaçóes do Partido em toda a América do Sul" (p. 104-105). Quanto ao germanismo, a indicaçăo é igualmente cristalina: "uma separaçấo orgânica dos nacionais alemăes e dos Volksdeutsche é necessária" (p. 105). Ainda quanto ao Partido, reiteram os representantes diplomáticos de que este "se conduza em público (...) dentro de estritos limites" (p. 105). Uma advertência explícita é feita no sentido da moderação quanto ao uniforme, à saudação alemã, à ostentação da insígnia e da bandeira", particularmente nas escolas" (p. 105).

Quanto às escolas e associaçôes de caráter cultural, é repetida de forma enfática a sugestâo de que sejam entregues exclusivamente a elementos Volksdeutsche e que não se procedam a atividades políticas em seu interior. É dada ênfase à necessidade de preparo de professores de origem alemã para atuarem nas escolas Volks- 
deutsche, inclusive com formação complementar na Alemanha, o que eidencia, mais uma vez, o caráter tático do recuo nas atividades estritamente políticas.

\section{4 - CONCLUSÃO}

Considerando-se os dois tipos de reação evidenciadoss pela diplomacia alemá diante da conjuntura antigermânica na América do Sul -- desencadeada sobretudo pela ofensiva político ideológica dos EUA no continente -- parece lícito supor que, pelo menos no que se refere aos aspectos analisados, há uma clara retraçăo da penetração alemã. Seja ela aparente impotência demonstrada na questão do controle norte-americano na imprensa, seja pela necessidade de um recuo, ainda que pretensamente temporário, nas atividades do partido -- evidenciada na questão da preservaçăo do germanismo -- parece claro o fato de que a diplomacia alemã sente de forma muito evidente a eficácia política do sentimento anti-alemão alimentado e, em grande medida, criado pela açáo norte-americana. De forma geral, a diplomacia germânica parece, então, reconhecer, ao menos temporariamente e quanto aos aspectos aqui analisados, que a manutençăo de suas posiçōes na América Latina requeria um cauteloso exercício de reorientaçăo política e um máximo de modéstia na fixação de prioridades.

* Depto de História - IFCH

PUCRS

Porto Alegre - RS

\section{NOTAS}

1. Cf. por exemplo, Conneil-Smith, Gordon. Los Estados Unidos y La America Latina. Mexico, Fondo de Cultura Economica, 1977, pp. 774 a 215.

2. Moura, Gerson. Autonomia na Dependência: A Política Externa Brasileira de 1935 a 1942.

Rio de Janeiro, Nova Fronteira, 1980, p. 136.

3. Ibid. p. 136.

4. Sobre a influência nazi-germânica no Brasil, cf., por exemplo, Seitenfuz, Ricardo A.S. O Brasil de Getúlio Vargas e a Formação dos Blocos 1930-1942. O Processo de Envolvimento Brasileiro na 2ªerra Mundial. São Paulo, Cia. Ed. Nacional, 1985. pp. 91 a 101.

5. As fontes aqui trabalhadas constituem a correspondência diplomática alemã publicada pelo

Departamento de Estado, o Foreign Ofrice e o governo francês, segundo a tradução $\mathrm{e}$ a edição no Brasil (O III Reich e o Brasil. Rio de Janeiro, Ed. Laudes, 1968). Todas as demais citações deste trabalho referem-se a esta obra, cujas páginas passamos a indicar diretamente no texto. 